\section{El turismo de cruceros de la isla de Cozumel, México: más allá del Caribe}

Q Lilia Susana Padilla y Sotelo

Departamento de Geografía Social, Instituto de Geografía, Universidad Nacional Autónoma de México, México.

\author{
Armando García de León Loza \\ Departamento de Geografía Económica, Instituto de Geografía, Universidad Nacional \\ Autónoma de México, México.
}

Recibido: 15 de diciembre de 2017. Aceptado: 16 de agosto de 2018.

\title{
Resumen
}

La localización de isla Cozumel (México) en el mar Caribe favorece la existencia de recursos naturales óptimos para la actividad turística. La infraestructura hotelera, así como otras diversiones, son todas de alta calidad. Sin embargo, en las costas mexicanas se localizan puertos relativamente similares, pero (excepto Cancún) están lejos de competir con Cozumel demostrando que el entorno físico favorable y equipamiento avanzado pueden ser insuficientes para integrarlos a las redes internacionales de cruceros. Del hecho anterior, se planteó como objetivo central del presente estudio identificar otros factores que explicaran el protagonismo de esta isla partiendo de referentes específicos, como la teoría de Causación Circular Acumulativa combinada con los efectos de propagación espacial del desarrollo, planteando aquí que una estructura económica especializada en el turismo sería un factor adicional y decisivo para explicar la importancia de este puerto. Después de analizar el caso de Cozumel bajo diversos enfoques, se encontró una economía especializada en los servicios; pero también la presencia de una población con alta capacitación para atender al turista se significó como factor sustancial de atracción para visitantes extranjeros.

\section{Why does Cozumel, Mexico, attract cruise ships: tourism beyond the Caribbean}

\author{
Abstract \\ The localization of the island of Cozumel (Mexico) in the Caribbean Sea has endowed \\ it with natural resources that are ideal for tourist activities. The infrastructure about \\ hotels and other attractions, is all of high quality. However, there are ports on the coasts
}

Palabras clave

Turismo Isla Cozumel Cruceros marítimos Especialización económica
Keywords 
of Mexico that are relatively similar but that are nowhere near competing with Cozumel. This shows that a favourable physical environment and innovative installations are not always sufficient to achieve a place on the circuit of international cruise ships. The main objective of the present work was to identify other factors that would explain the supremacy of Cozumel, on the basis of specific models such theory of Circular Cumulative Causation combined with the spatial spread effects of development. It is suggested here that an economic structure that is specialized in tourism would be an additional and decisive factor in explaining the importance of this port. Analysis of the case of Cozumel from various perspectives confirmed a functional economy that is specialized in the service industries. In addition, the presence of a population with advanced training in dealing with tourists has also been a substantial factor in the prominence that Cozumel has achieved about tourism attraction.

\section{Planteamiento y estado de la cuestión}

En términos de actividades relacionadas con el ámbito marítimo, México tiene una posición geográfica ventajosa al contar con litorales que le dan acceso a los dos océanos más importantes del planeta. En particular, su conexión con el Océano Atlántico es a través del Golfo de México y el Mar Caribe, donde este último destaca por el número significativo de atractivos naturales que lo caracterizan, tanto en sus zonas marítimas como en sus porciones insulares y peninsulares. Dentro de ese entorno natural se localiza la isla de Cozumel, lugar que viene aprovechando de tiempo atrás su ubicación geográfica para erigirse como uno de los destinos principales para cruceros marítimos en el ámbito turístico internacional y el más importante a nivel nacional.

Desde los años cuarenta del siglo pasado la estrategia nacional de desarrollo para México se ha sustentado en la industrialización. Sin embargo, algunos casos de enclaves aislados pero exitosos, como el de Cozumel, dieron pauta al gobierno mexicano para reconocer en el turismo una opción prometedora para captar divisas. Si bien desde hace tres lustros hay pocas dudas al respecto, la viabilidad de esta alternativa era menos obvia en los años sesenta. En especial debido a la dinámica propia de esta actividad cuando se desarrolla en lugares con regulaciones laxas, donde la mayor parte de los recursos captados se invierten de manera preferente en infraestructura o emigran hacia las matrices de las cadenas hoteleras y aeronáuticas. Cuando eso sucede, es común que cierto segmento de la población residente quede fuera de los beneficios más significativos, al tiempo que el medio físico que da vida a esta actividad sufre un deterioro constante (Cañada, 2000).

En ese escenario, a finales de los años sesenta los principales sitios de atracción para los visitantes extranjeros eran Acapulco, Puerto Vallarta y Cozumel con escasas visitas de cruceros con pasajeros. Pero en esa misma época los centros turísticos del Caribe y de la costa sur de los Estados Unidos tuvieron un auge importante, demostrando el potencial que representaba incorporarse al mercado turístico global. México intentó entonces adaptarse a las modalidades que demandaba la oferta internacional, pero por motivos diversos tuvo que esperar un par de décadas para que empezaran a funcionar nuevas opciones de primer nivel, encabezadas por Cancún en el mar Caribe, e Ixtapa y Huatulco en el Pacífico.

A pesar de esa infraestructura, hacia el final del siglo pasado fue evidente que disponer de importantes lugares turísticos era insuficiente para conseguir su reconocimiento como centros competitivos en la nueva esfera de la economía mundial. Encontrar lugares novedosos para ganar rentabilidad y acrecentar ganancias se convirtió en un desafío para las empresas dentro del capitalismo global. ${ }^{1}$ En consecuencia, la conexión

\section{Palavras-chave}

Turismo

Island cozumel

Cruzes marítimas

Especialização econômica
1. Rasgo distintivo del sistema capitalista global es la libre circulación de capitales. En este contexto los recursos naturales se mantienen en sus lugares; el flujo de personas encuentra trabas, pero los capitales, la información y las empresas pueden desplazarse (Soros, 1999). 
de los diversos segmentos de cada país a una red global era necesaria y sólo se lograría a partir de la competitividad de estos. Dicha condición debería alcanzarse mediante políticas de desregulación (favorecedoras del libre mercado) y las tecnologías de la información, como medios para asegurar la circulación de los capitales financieros (Castells, 1996). Para entonces era evidente la realidad postulada por Caravaca (1998), al respecto de que territorios desconectados de la internacionalización de la economía estaban en franco riesgo de quedar marginados del desarrollo.

En la actualidad se afirma que el transporte de cruceros (barcos turísticos para tráfico de pasajeros) es una modalidad de negocio dentro de la globalidad. Los lugares que quedan incluidos en las redes marítimas responden a condiciones de óptima ubicación y capacidad de los puertos como puntos aptos para realizar escalas, sin que las grandes cadenas navieras dejen de buscar nuevos destinos prometedores según los estándares de la red global (Aguilar et al., 2000). En el corto plazo, un puerto hoy exitoso puede quedar excluido de la red si se identifica otra opción más rentable y atractiva. Sin embargo, en el caso particular de Cozumel su proximidad a los Estados Unidos y Canadá lo favorece, ya que en esos países se ubica la mayor demanda de cruceros del mundo. Ante tal capacidad económica y tamaño del mercado potencial, las navieras aprovecharon la oportunidad de ampliar su ámbito de operación, incluso más allá de los destinos del Caribe incorporando puertos de las costas del Océano Pacífico, aumentando así la variedad de atractivos para los visitantes.

En este contexto toman relevancia lugares estratégicos para la navegación, como es el Canal de Panamá, tanto para los puertos caribeños en general como para Cozumel en lo particular, al quedar todos ellos integrados a rutas que habrían sido improbables de imaginar sin la presencia de esta opción que comunica los dos océanos más grandes del mundo. Aprovechando esta coyuntura, algunas de las navieras que tocan a Cozumel cruzan Panamá y prosiguen su trayectoria sobre el Pacífico a destinos como Punta Arenas (Costa Rica), Puerto Chiapas, Huatulco, Puerto Vallarta y Cabo San Lucas (México); de ahí siguen al norte hasta anclar en las costas occidentales de Estados Unidos. De hecho, existe el caso especial de una ruta que navega al sur con destino final en Perú. Por ende, el foreland (áreas con las que se relaciona un puerto a través del transporte) de Cozumel se amplió de manera excepcional.

Viene al caso recordar que a finales del decenio de 1970 comenzó la actividad turística de cruceros en México, la cual desde entonces mantiene un crecimiento constante. Sin embargo, de varias alternativas portuarias existentes, la isla de Cozumel se convirtió en el primer destino de cruceros del país y el segundo punto de atracción turística de la región caribeña, sólo atrás de Cancún (México) y en franca competencia con Bahamas. Dentro del entorno de volatilidad que presenta la economía global llama la atención que Cozumel haya logrado mantener esa posición.

Se sabe ya que el protagonismo logrado por Cozumel, como puerto de cruceros turísticos en la región del Caribe (e incluso considerado como uno de los más importantes del mundo en este rubro), responde a la disponibilidad de recursos naturales aptos para desarrollar el turismo, además de combinar condiciones poco comunes que favorecen la interacción entre regiones económicas de alta capacidad económica (las costas orientales de Estados Unidos y Canadá) y otras relativamente modestas (como Cozumel y otros puertos caribeños); además de aprovechar la cercanía del Canal de Panamá, factor éste último que le permite formar parte de un circuito de puertos privilegiados distribuidos sobre dos océanos.

Sin embargo, hasta aquí solo se han señalado factores ambientales y algunas externalidades favorables para este puerto, induciendo que falta dimensionar factores locales como son las condiciones intrínsecas de la población y la estructura económica de esa 
isla, buscando elementos adicionales para complementar la explicación del por qué su alta competitividad y permanencia de su protagonismo, investigación que se plantea como el principal objetivo del presente trabajo.

En función de la importancia que representa el turismo en el estado de Quintana Roo, al cual pertenece la isla de Cozumel, las autoridades gubernamentales del mismo, elaboraron un Modelo Integral de Gobierno que incluye entre sus planes de acción el Programa de Diversificación y Desarrollo del Turismo 2017 para desarrollar los importantes destinos con que cuenta, ser competitivo y líder de la actividad turística, que como motor del desarrollo económico y social del estado, genere bienestar para todos, para lo que se enfoca en apoyar a los municipios (Cozumel es uno de ellos) en la gestión de fondos, elaboración de planes de turismo y actividades relacionadas, así como en promover el trabajo conjunto de todos los sectores de la actividad turística y otorgar facilidades para su desarrollo, gestionar la apertura de nuevos vuelos en los aeropuertos de Cancún, Cozumel y Chetumal.

Del mismo modo busca impulsar la certificación de servicios turísticos y establecimientos con estándares de calidad nacionales e internacionales, establecer esquemas de colaboración con los sectores académico y empresarial para mejorar los perfiles de egreso educativo y de ingreso laboral, impulsar la competitividad del sector de cruceros en Quintana Roo, estimular en coordinación con los estados vecinos un producto turístico multidestino peninsular que unifique esfuerzos y se consolide como un producto competitivo en el Caribe y desarrolle conectividad aérea regional y así posicionar el Caribe Mexicano como una marca turística multiproducto y diversificada, por citar algunas de las acciones que incentivan el desarrollo del turismo en Cozumel y la entidad en la que se ubica (Gobierno de Quintana Roo (s/f).

\section{Metodología de análisis: estudio de los factores de desarrollo del turismo de cruceros en Cozumel}

Para concretar el objetivo central que sustenta esta investigación se propone una metodología de corte cualitativo - cuantitativo que analiza tres aspectos de la isla de Cozumel: a) Localización del lugar y rasgos geográficos; b) La infraestructura de que dispone; c) Su estructura social y económica. En los tres casos se plantean realidades y supuestos teóricos para procurar demostrar la importancia que alcanza cada uno de ellos.

Finalmente se hace énfasis en las características generales de su población y en las condiciones de especialización o diversificación de su economía, parámetros en los cuales se propone deben encontrarse elementos adicionales de justificación del lugar alcanzado por este puerto.

\section{Ubicación geográfica y recursos naturales}

La isla de Cozumel se localiza en el estado de Quintana Roo, situado al Oriente de la península de Yucatán, en México (Figura 1). Esa entidad federativa se ubica en un entorno internacional, al colindar al Sur con el vecino país de Belice y, además, rodeada por el Mar Caribe hacia donde presenta extensos litorales. Esta porción marina cuenta con las aguas más transparentes de los mares mexicanos. Esa particularidad natural explica la presencia de centros turísticos tan importantes como Cancún, los de la Riviera Maya y el propio Cozumel. Es considerada la tercera isla mexicana en tamaño y asienta la segunda localidad isleña más poblada. Está separada de la zona continental - peninsular por un estrecho canal de 17 kilómetros con profundidades hasta de 800 metros. 

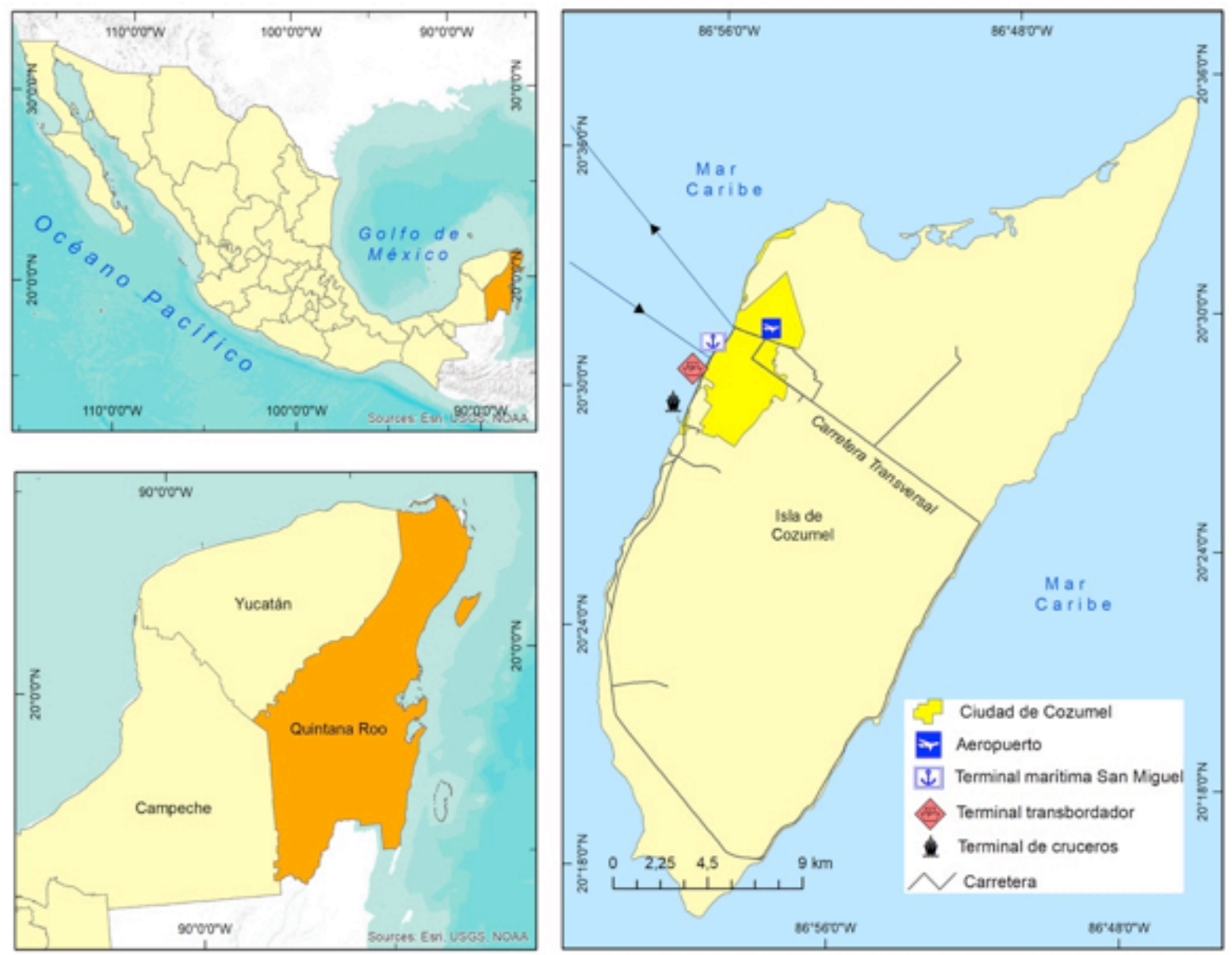

Figura 1. Localización geográfica de la Isla Cozumel. Fuente: Elaboración propia con datos de INEGI, Marco Geoestadístico Nacional 2010 (s/f).

Isla Cozumel o Cuzamil (en lengua maya) significa isla de las Golondrinas. Su superficie de $647 \mathrm{~km}^{2}$ resulta de sumar a la isla otros islotes y cayos, además de dos porciones ubicadas en la zona continental peninsular. En una de ellas se localiza la empresa "Calizas Industriales del Carmen" productora de materiales para la construcción, dirigidos a mercados de alto nivel económico en México y los Estados Unidos. Además, ese lugar provee servicios para el turismo y la industria regional en la Terminal Marítima de Punta Venado y traslada pasajeros y mercancías desde el continente. La segunda porción comprende al Parque Ecológico Xel-Ha, zona comercial turística en tierra firme conocida como el acuario más grande del mundo, cualidad que la convierte en otro centro de atracción turística en plena Riviera Maya, ${ }^{2}$ gracias a los servicios que ahí se ofrecen.

En su parte más ancha la isla de Cozumel tiene 15 kilómetros, mientras que se extiende otros 45 kilómetros a lo largo. Se ubica en las coordenadas $20^{\circ} 16^{\prime}$ Norte y $87^{\circ}$ longitud Oeste, al sur del Trópico de Cáncer, de donde le corresponde clima del tipo Am (cálido húmedo con lluvias en verano) y temperatura media anual entre 26 y $28^{\circ} \mathrm{C}$. Los valores más bajos ocurren en enero $\left(19^{\circ} \mathrm{C}\right)$, mientras las condiciones más cálidas $\left(31^{\circ} \mathrm{C}\right)$ van de mayo a julio. Su promedio anual de lluvia es de $1.504 \mathrm{~mm}$ con estacionalidad de mayo a octubre, volumen que resulta ser el doble del promedio nacional. Además de proveer de agua a la isla también aporta un grado de humedad aceptable para un sitio de esparcimiento. La ocurrencia de tormentas tropicales y huracanes (de mayo a octubre)

2. La principal atracción es la Caleta XeL-Ha, resultado de un rio subterráneo colapsado. Ahí se practica snorkel, buceo y kayak. A corta distancia se encuentran el parque La Cueva Maya, la Gruta de Ixchel y La Gruta “El Dorado”, entre otros lugares de excepcional belleza. 
parecen ser una adversidad menor, a pesar de que la región donde se encuentra es la tercera del país por su número de ciclones (Pozo et al., 2011). Son relativamente comunes los frentes fríos (de noviembre a marzo) a pesar de los cuales rara vez se registran temperaturas debajo de los $18^{\circ} \mathrm{C}$. Son condiciones idóneas para el turismo de playa, por lo que este clima se reconoce como uno de los principales atractivos de Cozumel.

En cuanto a sus suelos, la isla pertenece a la provincia fisiográfica denominada Península de Yucatán, la cual se caracteriza por planicies prolongadas formadas de piedra caliza coralina y suelos arenosos. La elevación natural más importante en la isla está a menos de 13 msnm. Además, forma parte del Sistema Arrecifal Mesoamericano, ${ }^{3}$ segunda formación mundial de este tipo y solo inferior a la Gran Barrera de Coral que se encuentra en Australia. Comienza en México (en el estado de Quintana Roo), se extiende por las costas de Belice, Guatemala y Honduras (Aguilar et al, 2000).

En la isla de Cozumel no existen corrientes superficiales de agua debido a la permeabilidad del suelo, pero en la zona sur se localizan entradas de agua marina que han tomado el nombre de Laguna de Colombia y Laguna de Chankanab; ${ }^{4}$ asimismo en la zona norte está la Laguna Ciega y una corriente (el río La Plata) de extensión limitada, entre otros cuerpos de agua. Cuenta con los típicos pozos denominados "cenotes"5 que dieron fama a la cultura maya. En territorio marítimo se encuentran abundantes recursos para la pesca deportiva y el buceo.

Su flora se caracteriza por vegetación dominante de selva mediana subperennifolia. Los árboles presentan alturas de 15 a 25 metros y las palmeras forman parte de los estratos bajo y medio. La fauna constituye un elemento biótico tan importante como lo es el medio vegetal; al respecto, la dinámica de distribución de uno condiciona al otro. La parte terrestre de la isla alberga anfibios, reptiles, aves y mamíferos, (INE, 1998). Su condición insular le facilitó ser lugar de residencia de 30 especies y subespecies endémicas, terrestres y de agua dulce, con otras 12 especies de distribución restringida (Ayuntamiento de Cozumel, 2005-2008). La Isla está clasificada por Conservation International ${ }^{6}$ como área clave de biodiversidad, tanto por su aislamiento como por el alto número de especies y la abundancia de endemismos, riquezas naturales que se suman a los demás atractivos locales.

\section{Infraestructura}

El segundo factor que revisar, para explicar la relevancia portuaria para arribo de cruceros, es la disponibilidad de infraestructura y área de influencia de Cozumel. Puede analizarse tanto en el entorno de organización y características portuarias (que facilitan el arribo de cruceros), como también a modo de soporte de los servicios turísticos disponibles de alto nivel. En ambos rubros se reconoce a esta isla como un lugar de clase mundial (API, QROO, 2013) por cumplir las exigencias internacionales. En este sentido es importante señalar la especialización de sus instalaciones, construidas específicamente para recibir cruceros turísticos de grandes dimensiones, sin la complicación de compartir el mismo puerto con otro tipo de navíos.

Esta circunstancia lleva a reflexionar al respecto de que contar con la infraestructura adecuada para poder interactuar (e incluso competir) con las regiones vecinas de alto nivel económico, puede generar una dinámica capaz de favorecer que parte de la riqueza de aquéllas llegue aquí. Y de contar con esos atributos de equipamiento (y otros más de tipo social y económico que se revisarán más adelante) un puerto podrá integrarse a un sistema generador de diversas interacciones, algunas directas y otras indirectas, que van desde las que se producen a través del sistema de transporte terrestre y marítimo (Navarro, 1994), como resultado de los procesos territoriales generados por el mercado (producción, distribución, consumo, etcétera).
3. El Sistema Arrecifal Mesoamericano es sitio de una iniciativa internacional de conservación del Fondo Mundial para la Naturaleza (World Wide Fund for Nature) WWF, por sus siglas en inglés.

\section{Término maya que sig-} nifica pequeño mar.

5. Término que proviene de la palabra maya "dzonot", que significa "abismo"; son pozos o dolinas inundadas de agua dulce formados por la erosión de la piedra caliza, suave y porosa de origen kárstico. Para el mundo maya eran fuentes de vida que proporcionaban el líquido vital, además de ser una entrada al inframundo.

6. Organización altruista enfocada a la preservación de espacios naturales vírgenes como reliquias del pasado. 


\section{Actividad portuaria y alcance territorial}

Cozumel cuenta con una moderna infraestructura portuaria. Integra tres terminales internacionales de cruceros, una terminal de transbordadores y un muelle menor en San Miguel, los cuales brindan servicio a embarcaciones de conexión, turísticas y de pasajeros. Las instalaciones referidas están bajo la Administración Portuaria Integral local, junto con los puertos de Isla Mujeres, Cancún, Chetumal y Playa del Carmen (API QROO, 2013).

Hacía los años setenta del siglo pasado comenzó en Cozumel la actividad turística de cruceros, la cual tuvo un dinámico crecimiento en las décadas de los ochenta y noventa, hasta convertirse en el importante destino turístico que es hoy. Por ejemplo, en 2006 arribaron 1.058 cruceros con 2,6 millones de turistas, para 2016 ingresaron 3,6 millones por este medio, cifra que para a 2017 se prevé sobrepase los cuatro millones (Valadez y Juárez, 2017). Es el principal destino del país en esta modalidad, muy por encima de otras terminales que reciben cruceros (Figura 2). Se considera que cerca del $80 \%$ de los pasajeros y entre 40 y $60 \%$ de la tripulación de cada crucero desembarcan y en su tiempo de estancia demandan todo tipo de servicios (Ayuntamiento de Cozumel, 2005-2008). Cabe señalar que la mayoría de los turistas de cruceros que exploran la Isla lo hacen a través de tours organizados por operadores locales.

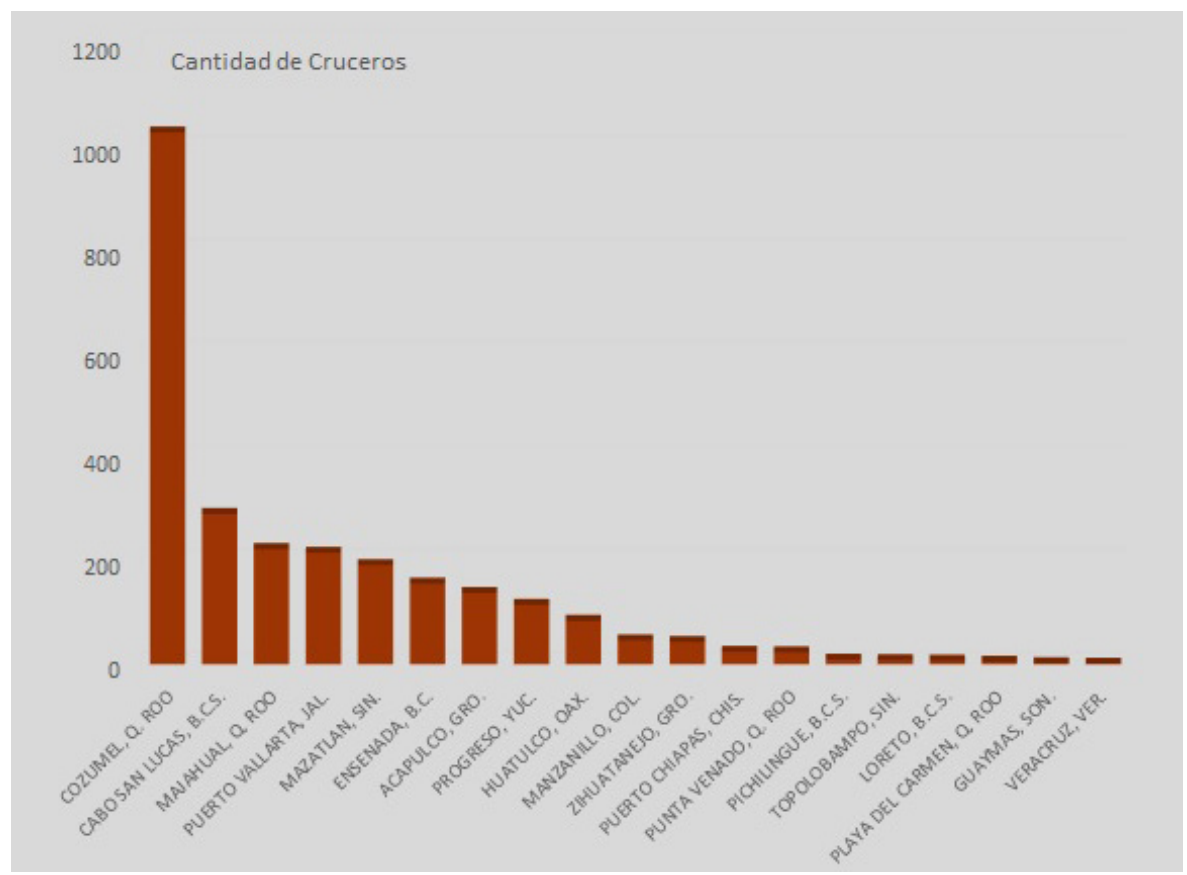

Figura 2. Comparativo de los destinos que reciben cruceros en México. Fuente: SCT, Anuario Estadistico de Puertos 2011.

Según cifras oficiales, solo entre enero y marzo de 2013 llegaron 332 cruceros con más de 1,3 millones de turistas, quienes generaron una derrama económica superior a 106 millones de dólares gracias a su gasto promedio de 80 dólares por persona (SCT, 2013).

Para 2013 en Cozumel funcionaban cincuenta establecimientos hoteleros, la mayoría de ellos clasifican de cuatro estrellas a Gran Turismo. Hay disponibilidad de hoteles con prestigio internacional como Iberostar Occidental, Wyndham, Intercontinental, Meliá, además de franquicias nacionales como Palace Resorts, Fontan, Fiesta Americana, Park Royal y el Cid, que aunados a los hoteles de inversión local (El Cozumeleño, Playa Azul, Cozumel \& Resort, Casa del Mar, Casa Mexicana, Villablanca y los de tipo boutique Hacienda San Miguel y Vista del Mar) aseguran la satisfacción de cualquier turista. 
En cuanto a las rutas que se desplazan por el Caribe, los principales puntos que tocan los cruceros son Cozumel, Belice, Gran Caimán, Jamaica y Roatan (en Honduras).

Son varias las travesías que parten de puertos situados en Florida (Tampa, Miami o Fort Lauderdale) para llegar a las Bahamas, St. Thomas, Islas Vírgenes y Puerto Rico. Otras salen de Nueva Orleans hacia Cozumel, Playa del Carmen, Grand Caimán, Key West, Jamaica, República Dominicana, Belice y Costa Rica (Figura 3).

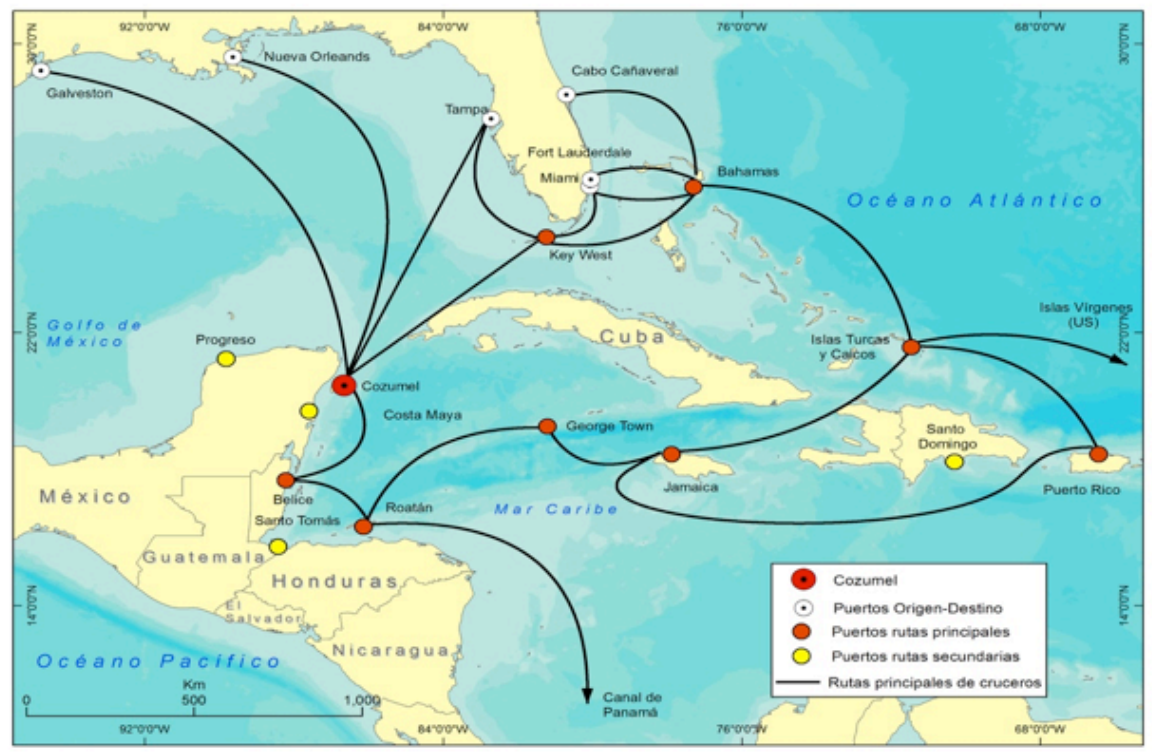

Figura 3. Ubicación de Cozumel como vía de cruceros en el Caribe. Fuente: Elaborado a partir de la base de datos en línea de cada naviera, cruceros disponibles 2013-2014.

Incluso, como se mencionó, se cuenta con alternativas navieras con la capacidad para ampliar sus destinos al Océano Pacifico, cruzando por Panamá y llegando a Costa Rica, México y Estados Unidos por la costa Oeste, extendiéndose hasta Canadá. Además, existe una ruta que alcanza Perú (CESTUR, s/f) (Figura 4). 


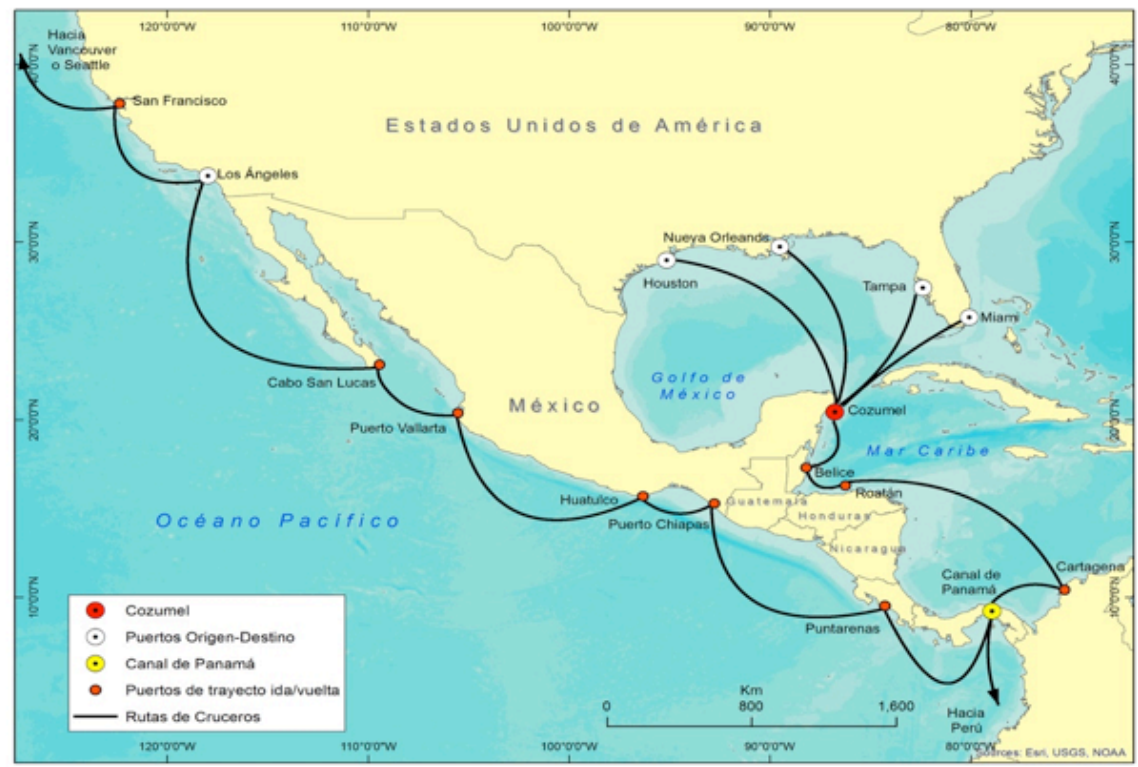

Figura 4. Destinos en conexión con Cozumel considerando el cruce por el Canal de Panamá. Fuente: Elaboración propia a partir de la base de datos en línea de cada naviera, cruceros disponibles 2013-2014

Las navieras ofrecen a menudo itinerarios largos (de 10 a 14 días), aunque existen otros limitados a no más de 7 días en los cuales es difícil visitar de manera pausada tantos destinos atractivos (Padilla y Molina, 2013).

A pesar del escenario favorable que se desprende de los párrafos anteriores para este tipo de viajes, el turismo de cruceros debe calificarse como una actividad que genera cierta incertidumbre contexto en el cual, para evitar ser afectado, cualquiera de estos puertos está obligado a conservar la clientela con mayor capacidad económica, al tiempo que debe asegurar el mantener esta actividad de modo sustentable, protegiendo los recursos naturales que son su principal atractivo.

En 2013 eran doce las navieras mundiales que tenían a Cozumel como uno de sus destinos destacados (Cuadro 1), aparte de otras cuyas llegadas eran ocasionales. Desde luego que la demanda de servicios de navegación no se limita a visitantes de América del Norte, ya que se reportan también importantes flujos de turistas europeos y asiáticos. Conviene destacar que las "tres grandes" compañías internacionales de cruceros (Carnival, Royal Caribbean International y Princess), controlan cerca del 70 por ciento de los mercados correspondientes a los Estados Unidos y Canadá.

Cuadro 1. Navieras que arribaron a Cozumel en 2013 y programadas para 2014. Fuente: Elaborado a partir de la base de datos en línea de cada naviera, cruceros disponibles 2013-2014.

\begin{tabular}{|l|c|}
\hline Navieras que arriban a Cozumel \\
\hline Princess Cruises & Holland America Line \\
\hline Crystal Cruises Inc & Carnival Cruise Line \\
\hline Celebrity Cruises & Aida Cruises \\
\hline Silver Sea Cruises Ltd & Royal Caribean \\
\hline Oceania Cruises & Norwegian Cruises Line \\
\hline Disney Cruises & \\
\hline
\end{tabular}

Además de la intensidad de los flujos registrados, a futuro hay interés por parte de compañías importantes, como Star Cruises (Malasia), de situarse entre las mayores navieras, a partir de viajeros que provienen de Asia. El mercado asiático representa 
un notable potencial debido a la prohibición que enfrentan en sus países para jugar en casinos, mientras que en puertos caribeños pueden dedicarse a esta actividad mientras sus familiares disfrutan otras diversiones que ofrecen los barcos.

Conviene mencionar la existencia de otro tipo de actividad portuaria en Cozumel bajo la modalidad de transbordadores, diseñada para comunicar la isla con el continente. Las estadísticas oficiales (SCT, 2002-2013) indican que por este medio se desplazan entre 1,3 y 1,5 millones de pasajeros por año. El Cuadro 2 muestra el registro de viajeros en 2010 provenientes de Punta Venado, el cual funciona como puerto de carga, entrada y salida de vehículos particulares y comerciales. Además, hay otra vía a modo de ferrys, entre Playa del Carmen y Cozumel, para traslado de personas y mercancías con la tierra firme más cercana. Ambos medios de transporte trasladaron en el 2010 a 1,3 millones de personas.

Cuadro 2. Movimiento de pasajeros en transbordadores. Fuente: Secretaría de Comunicaciones y Transportes, 2010

\begin{tabular}{|l|c|c|c|}
\hline Ruta & Arribos & Pasajeros & $\begin{array}{c}\text { Promedio } \\
\text { (Pasajeros/Arribo) }\end{array}$ \\
\hline Totales & 62.889 & 5.134 .664 & 81 \\
\hline Transbordadores & 8.354 & 733.673 & 87 \\
\hline Punta Venado Cozumel & 1.334 & 125.478 & 93 \\
\hline Cozumel Punta Venado & 1.343 & 137.599 & 101 \\
\hline Costeros & 54.535 & 4.400 .991 & 80 \\
\hline Cozumel Playa del Carmen & 4.699 & 1.135 .555 & 241 \\
\hline Playa del Carmen Cozumel & 4.749 & 1.160 .555 & 243 \\
\hline
\end{tabular}

La planeación local alcanza un nivel de previsión significativo, luego de que la terminal para el tráfico de transbordadores y de ferrys (llamados también costeros), se encuentra situada en lugares alejados de las instalaciones dedicadas a atender cruceros turísticos. Esta separación evita que los visitantes que bajan de un crucero enfrenten inconvenientes al desembarcar o reembarcarse.

\section{Integración dentro de la red portuaria de cruceros turísticos}

A partir de las cifras y datos presentados en los apartados anteriores puede evidenciarse que las ventajas de Cozumel para asentar un puerto competitivo nada tienen de coyuntural, ya que responden en lo primordial a su proximidad al litoral oriental de los Estados Unidos de América. Por ejemplo, lo separan solo mil kilómetros de Tampa, Florida; distancia moderada para la capacidad actual de los cruceros marítimos. De igual manera tiene a su alcance el oriente de Canadá, por lo cual cubre ambas costas reconocidas por asentar las zonas más ricas del planeta en términos económicos. En este contexto, es necesario destacar también la relativa cercanía de Cozumel al Canal de Panamá.

En términos de las escalas de accesibilidad referidas, la posición geográfica de Cozumel está asociada con ciertas ventajas, tal y como los postulan especialistas como Glade y Anderson (1963:16), quienes al estudiar las zonas fronterizas entre México y los Estados Unidos concluyeron que "... la proximidad geográfica a los grandes y expansivos mercados estadounidenses ha ayudado enormemente a la expansión de las exportaciones mexicanas de productos primarios".

Este hecho permite postular que la porción de mar que separa a Cozumel de las costas orientales de los otros dos países de América del Norte puede aceptarse como un espacio continuo y sin obstáculos, favorable para la comunicación directa (en este caso por vía marítima) entre las costas respectivas. Si de igual manera se acepta al turismo 
como un producto primario, se tendrá un escenario que favorece la integración y complementariedad entre esos espacios vecinos, ya que Cozumel fundamentalmente ofrece servicios básicos (recursos naturales), equivalentes en términos generales al concepto de producto "primario".

Del mismo modo, las inversiones realizadas por el gobierno mexicano y empresas privadas que operan el turismo en Cozumel la han dotado de infraestructura suficiente para ser competitiva dentro de la red de cruceros caribeños. Esta realidad se apega a las opiniones de diversos teóricos, quienes aseveran que las relaciones comerciales entre regiones con diferentes niveles de desarrollo suelen dejar en riesgo a la de menor nivel (en este caso sería Cozumel), ante las ventajas competitivas y alta disponibilidad de capital que suele poseer la región más avanzada (Myrdal, 1959 y Hirschman, 1958). Sin embargo, cuando la región con atraso logra interaccionar de manera eficiente con la otra es viable lograr un efecto de "capilaridad o infiltración que genera beneficios económicos a dicha región" tal como lo postula Asuad (2001: 69) al citar a Hirschman.

De manera específica, al convertirse en regiones complementarias y dejar de competir entre sí el efecto de infiltración es muy probable se desplace hacia la región pobre. Queda demostrado que Cozumel y el resto de la región caribeña, donde se asientan los demás puertos turísticos de prestigio internacional, han ganado en términos económicos con la llegada de recursos del turismo procedente de las regiones más ricas del mundo.

Al revisar la localización geográfica es necesario dimensionar también el papel del Canal de Panamá, como factor estratégico para dar a Cozumel el protagonismo que ha alcanzado a nivel de terminal de cruceros turísticos. Las cifras que se presentan en el Cuadro 3 ilustran la tendencia positiva que caracteriza esta modalidad marítima. Además, la información del tabulado referido demuestra que la cercanía del Canal de Panamá permite un incremento notable del turismo de cruceros de la región caribeña en general. Por ende, puede reconocerse esa vía de comunicación como elemento catalizador de la economía regional, reconociéndose que también ha redituado ingresos significativos a la República de Panamá. Se trata pues de un círculo "virtuoso" donde, en principio, parece que todas las partes salen beneficiadas.

Cuadro 3. Total de visitantes de cruceros ingresados a Panamá según mes por variación absoluta y relativa. Años: 2010-2013. Fuente: Cálculos propios con datos de República de Panamá. Autoridad de Turismo de Panamá. Boletín Estadístico 2013.

\begin{tabular}{|l|c|c|c|c|c|c|}
\hline & \multicolumn{3}{|c|}{ Tráfico de Cruceros Marítimos (total de pasajeros) } & \multicolumn{2}{c|}{ Variación (2013 / 2010) } \\
\hline Meses & $\mathbf{2 0 1 0}$ & $\mathbf{2 0 1 1}$ & $\mathbf{2 0 1 2}$ & $\mathbf{2 0 1 3}$ & Absoluta & Relativa \\
\hline Enero & 51.223 & 70.281 & 60.152 & 59.983 & 8.760 & $17 \%$ \\
\hline Febrero & 45.001 & 61.284 & 52.573 & 50.925 & 5.924 & $13 \%$ \\
\hline Marzo & 40.735 & 60.307 & 38.632 & 41.758 & 1.023 & $3 \%$ \\
\hline Abril & 32.006 & 50.803 & 37.816 & 38.576 & 6.570 & $21 \%$ \\
\hline Mayo & 5.377 & 17.198 & 12.178 & 12.614 & 7.237 & $135 \%$ \\
\hline Julio & 3.976 & 6.423 & 4.014 & 6.657 & 2.681 & $67 \%$ \\
\hline Junio & 4.675 & 3.841 & 4.358 & 5.683 & 1.008 & $22 \%$ \\
\hline Agosto & 3.744 & 5.923 & 5.997 & 10.554 & 6.810 & $182 \%$ \\
\hline Septiembre & 7.634 & 8.923 & 4.864 & 17.157 & 9.523 & $125 \%$ \\
\hline Octubre & 31.394 & 42.925 & 15.210 & 21.679 & -9.715 & $-31 \%$ \\
\hline Noviembre & 52.285 & 52.284 & 39.887 & 48.336 & -3.949 & $-8 \%$ \\
\hline Diciembre & 53.150 & 49.083 & 58.756 & 59.583 & 6.433 & $12 \%$ \\
\hline Totales & 331.200 & 429.275 & 334.437 & 373.505 & 42.305 & $13 \%$ \\
\hline
\end{tabular}




\section{Estructura Social y Económica}

Este tercer factor reúne componentes vitales, tales como el nivel de adaptación y de competencia del puerto y localidad en donde se sitúa y el papel que desempeña en términos sociales dentro de la red global en la cual está inserto. En la misma línea puede aplicarse el concepto de Castells (1999), en cuanto a que un puerto logrará integrarse en lo que denomina espacio de flujos. ${ }^{7}$ Lo anterior toma relevancia ante el hecho de que la población es afectada por decisiones que se toman más allá de su entorno, pero con repercusiones sociales y económicas a nivel local.

Además del comportamiento de los parámetros demográficos comunes, el perfil sociocultural de la población se suma a la esfera económica, ya que al cumplir con cierta eficiencia las funciones para las cuales desarrolla sus actividades se convierte en un atractivo adicional para los visitantes. El personal ocupado en labores relacionadas con el turismo deberá mostrar dinamismo y una capacitación aceptable (Barragán, 1987).

Al mismo tiempo que se cuenta con una población con vocación hacia el turismo, también se esperaría encontrar en Cozumel una clara especialización económica centrada en las actividades turísticas desarrolladas aquí. Su condición de isla favorece su vocación turística, dado que esta actividad se desarrolla a cabalidad, sin necesidad de compartir ese protagonismo con otros sectores relevantes. Así, aplicando los conceptos de Asuad (Op. Cit.), el peso de ciertos rubros, como transporte, comercio y servicios de hospedaje, comida y esparcimiento tendrían que ser protagónicos en este lugar. A partir de esa especialización significativa se inferirá, incluso, el nivel de internacionalización y globalización de la economía local. En consecuencia, de darse los dos supuestos (población capacitada y estructura económica centradas en el turismo) la isla en su conjunto demostraría ser, tal vez, un caso único en la región caribeña.

\section{Población}

Debido al aislamiento natural que enfrenta por su condición de isla y a cierta carencia de recursos naturales de interés para la industria, a lo largo de su historia Cozumel registró un crecimiento poblacional modesto. Esta situación cambió de manera sustancial en los años setenta, al momento en que el turismo se erigió como actividad sustantiva, luego de que en 1974 las autoridades gubernamentales reconocieron al entonces Territorio de Quintana Roo como una entidad federativa más de México.

Antes de 1950 esta isla contaba con menos de 2.000 residentes, pero a partir de ese momento empezó a duplicar su población cada diez años, como lo demuestran las cifras censales respectivas, sin que ello representara todavía volúmenes importantes de nuevos inmigrantes. En contraste, para 1980 la población llegó a 19.044 habitantes para aumentar a casi 34.000 diez años después, de manera tal que el año 2000 presentó cerca de 60.000 residentes (Cuadro 4). En el año 2010 sumaban 77.236 residentes, concentrados en la localidad de Cozumel. Que de acuerdo con estimaciones realizadas por los autores podrán llegar hasta los 84.000 habitantes para el 2020.

Cuadro 4. Dinámica de la población del Estado de Quintana Roo y del municipio y localidad de Cozumel, 1980 -2010. Fuente: Estimaciones propias con datos de INEGI s/f), Censos de Población 1990, 2000 y 2010 (s/f). e) Valores estimados.

\begin{tabular}{|l|c|c|c|c|c|c|}
\hline Unidad Política & $\mathbf{1 9 9 0}$ & $\mathbf{2 0 0 0}$ & $\mathbf{2 0 1 0}$ & $\mathbf{2 0 1 8 e}$ & $\mathbf{2 0 2 0 e}$ & $\begin{array}{c}\text { Tasa de crecimiento } \\
\mathbf{1 9 9 0}-\mathbf{2 0 1 8}\end{array}$ \\
\hline Estado de Quintana Roo & 493.277 & 900.000 & 1.325 .578 & 1.650 .000 & 1.730 .000 & $4,41 \%$ \\
\hline Municipio de Cozumel & 44.903 & 64.000 & 79.535 & 86.300 & 88.000 & $2,36 \%$ \\
\hline Cozumel (localidad) & 33.884 & 61.000 & 77.236 & 82.600 & 84.000 & $3,23 \%$ \\
\hline Cozumel (loc.)/Total Estatal & $6,9 \%$ & $6,8 \%$ & $5,8 \%$ & $5,0 \%$ & $4,9 \%$ & \\
\hline
\end{tabular}

7. También se le puede denominar red global. 
Ante las serias limitaciones isleñas en cuanto a disponibilidad de espacio y recursos básicos, los importantes volúmenes de población y el alto ritmo de crecimiento ilustrados en el Cuadro 4 sólo pueden explicarse por la bonanza creciente de las actividades relacionadas con el turismo. Para 2010, la localidad de Cozumel fue la única población urbana del municipio. El siguiente asentamiento importante (Las Fincas), apenas contabilizaba 746 personas (INEGI s/f, Censo de 2010) todo ello dentro de una muy reducida frontera de posibilidades de desarrollo urbano.

A nivel municipal Cozumel resalta en algunos parámetros demográficos. Por ejemplo, hay un claro predominio de hombres (relación hombres/mujeres=103,0), comportamiento inverso al del promedio nacional (relación $\mathrm{H} / \mathrm{M}=95,4$ ); algo similar sucede en el Îndice de Envejecimiento (población de adultos mayores respecto a población joven e infantil) donde esta isla alcanza una relación de sólo 18,4, poco significativa ante el valor de 30,9 que se tiene a escala nacional. De hecho, en todas las variables relativas a población joven Cozumel presenta valores relativamente elevados.

Otro tema de primera importancia con respecto a la población es el nivel educativo, ya que un destino de clase mundial requiere de gente con preparación para atender debidamente los servicios especializados que ahí se prestan. En este rubro se registró un grado de escolaridad municipal de 9,1 años de estudios, que supera el promedio nacional de 8,6 años. En cuanto a la población de 15 años o más predomina la población con 10,5 por ciento del promedio nacional (INEGI s/f, Censo de 2010), niveles de estudios más allá de la educación básica, como es el caso de la enseñanza a nivel medio superior donde 16,4 por ciento de la población local la completó.

Viene al caso reconocer que, además de sus playas, mar y clima óptimos para el esparcimiento, parte del aceptable nivel cultural de la población responde a que Cozumel posee una fuerte herencia histórica. Fue visitada desde tiempos prehispánicos por habitantes del continente, por lo cual ubica una serie de sitios arqueológicos mayas, como son los de San Gervasio, Santa Rita, Ixpal Barco, Xhanan, el Castillo Real y la Tumba del Caracol. Esa concentración de lugares en una superficie tan poco extensa es prometedora para el turismo.

Otro ejemplo del nivel cultural local fue la idea de celebrar ahí uno de los carnavales más importantes de todo México. En este contexto, es importante señalar que un atractivo de Cozumel es su tradición prehispánica. Sin embargo, las últimas cifras censales indican que sólo 11 por ciento de la población habla alguna lengua nativa, evidencia de cierta pérdida en identidad cultural. Esta situación se confirma al encontrar que solo poco más del uno por ciento de los residentes menores de 20 años son bilingües de la lengua maya originaria del lugar y la región, mientras que ese valor supera el $17 \%$ al tomar en cuenta mayores de 19 años, demostrando con ello el alejamiento de los estratos más jóvenes en intentar preservar las lenguas originarias.

El potencial de opciones se ha desarrollado a plenitud al instituirse también el festival Ironman con rutas de natación, ciclismo y carrera al cual acuden numerosos participantes de diversas naciones, por lo cual ya cumplió cinco años de efectuarse, eventos planteados y desarrollados por la gente del lugar.

En el mismo orden de ideas debe señalarse que por parte de la Universidad de Quintana Roo, entidad a la que pertenece la Isla de Cozumel, existe interés por desarrollar carreras afines al turismo en el Campus Cozumel, se proporciona la licenciatura sobre Gestión de Servicios Turísticos para capacitar personal local enfocado hacia turismo de altura, contemplando actividades como hotelería, gastronomía, agencias de viajes, parques naturales y operadoras turísticas, así como también se imparte la maestría en Gestión Sustentable del Turismo con énfasis en manejo de empresas turísticas y sustentabilidad de áreas protegidas, que contribuyan al desarrollo sustentable del turismo. 
Asimismo, dado que el factor humano es clave para el desarrollo del turismo y su competitividad, se requiere que el personal que labora en el sector del turismo, sea especializado con dominio de diferentes idiomas, en este caso, es esencial el manejo de inglés, de manera que se fomentan las capacidades de los prestadores de servicios del sector en comunicación oral: En consecuencia los guías de turismo deben de estar debidamente acreditados para poder laborar de lo contrario incurren en faltas, y uno de los puntos que se les exige es la acreditación del idioma inglés (SECTUR, 2013). En relación con este tema, debe señalarse que gran proporción de personas que trabajan en el sector turismo, aun cuando sean empleos de menor relevancia, se han visto en la necesidad de aprender inglés empíricamente, para así atender la demanda del turismo internacional. Derivado de todo lo anterior existe una proporción elevada de la población es bilingüe de una lengua extranjera, ya que Cozumel vive prácticamente del turismo.

\section{Economía}

Uno de los supuestos hipotéticos que debería explicar de mejor manera el desempeño exitoso de Isla Cozumel, se refiere a un claro predominio del turismo y actividades colaterales. En ese tenor, tanto por los cruceros de la red del Caribe especialmente de pasajeros internacionales y también debido a los turistas nacionales que ingresan por otras vías, podría esperarse una especialización sobrada hacia este sector.

De entrada, el principio establecido por Asuad (2001), sobre el peso notable de ciertos rubros relacionados sin duda con el turismo, se cumple de manera cabal. Por ejemplo, el empleo sectorial refleja la vocación del lugar hacia los servicios, tal y como lo indica el Cuadro 5.

Cuadro 5. Comparativo de distribución sectorial de población ocupada, 2010. Fuente: Cálculos propios con datos de INEGI, (s/f) Censo de 2010

\begin{tabular}{|l|c|c|c|c|}
\hline Unidad Territorial & Sector Primario & $\begin{array}{c}\text { Sector } \\
\text { Secundario }\end{array}$ & $\begin{array}{c}\text { Sector } \\
\text { Comercio }\end{array}$ & Sector Servicios \\
\hline Cozumel & 1,6 & 13,4 & 21,6 & 62,1 \\
\hline Promedio Nacional & 13,4 & 24,4 & 19,2 & 41,7 \\
\hline
\end{tabular}

En ese tabulado se puede apreciar la mínima presencia del sector primario, resultado lógico ante la pequeña extensión y pobre aptitud de la isla para asentar una agricultura o ganadería de alguna importancia. Aunque en menor medida, algo similar sucede en el sector de manufacturas y construcción, donde el promedio nacional supera en casi el doble los valores de Cozumel. Sin embargo, a pesar de esa inferioridad, la producción secundaria puede considerarse más relevante de lo esperado, hecho que podrá corroborarse y entenderse un poco más adelante. En contraste, mientras la media del país apenas se acerca al 61 por ciento de ocupados en comercio y servicios, en la isla ese valor supera 83 por ciento.

Al revisar ahora las cifras relativas al valor monetario de producción sectorial se encuentra la siguiente distribución: Sector Primario: 0,1 \% (Agricultura, ganadería, caza y pesca). Sector Secundario: 21,4\% (Industria manufacturera, construcción, electricidad). Sector Terciario: 78,5\% (Comercio y servicios, incluyendo turismo) (INEGI, Censo de 2010) (Figura 5). 


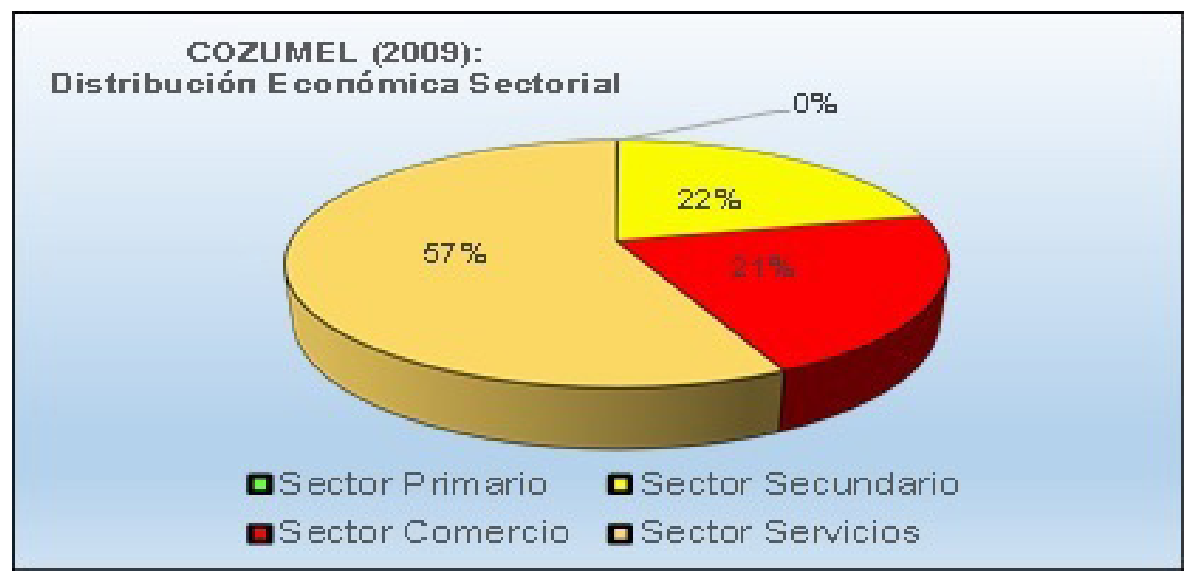

Figura 5. Estructura Económica por valor de producción. Fuente. Elaboración propia con base a datos de Censo de Población y Vivienda 2010, INEGI, (s/f).

Es posible analizar con mayor detalle las cifras presentadas antes. Sin embargo, una manera eficiente y más precisa para determinar el posible grado de especialización de Cozumel (al respecto de actividades turísticas) puede ser el determinar el peso de las principales subramas de su economía en el rubro de ingresos captados por la venta de bienes y servicios, para lo cual se presenta el Cuadro 6.

Cuadro 6. Municipio de Cozumel: Total de ingresos por venta de bienes y servicios del turismo y otras actividades económicas, 2009. Fuente: Cálculos propios con datos de INEGI, (s/f) Censo Económico 2009.

\begin{tabular}{|l|c|c|}
\hline Municipio y Subramas de actividad & $\begin{array}{c}\text { Total de Ingresos (miles } \\
\text { de dólares E.U.A.) }\end{array}$ & $\begin{array}{c}\text { Participación } \\
\text { en el total } \\
\text { de ingresos }\end{array}$ \\
\hline Total de ingresos por la actividad & 665.590 .2 & $100,0 \%$ \\
\hline Comercio al mayoreo y al menudeo & 256.050 .9 & $38,5 \%$ \\
\hline $\begin{array}{l}\text { Hoteles, restaurantes y otros servicios } \\
\text { turísticos }\end{array}$ & 155.019 .1 & $23.3 \%$ \\
\hline Transporte y Comunicaciones & 34.739 .2 & $5,2 \%$ \\
\hline Edificación y servicios inmobiliarios & 16.437 .9 & $2,5 \%$ \\
\hline Subtotal de principales subramas turísticas & 462.246 .9 & $69,4 \%$ \\
\hline & \multicolumn{2}{|l}{} \\
\hline Industrias de Manufactura & 59.137 .5 & $8,9 \%$ \\
\hline Otras subramas de actividad & 203.343 .3 & $30,6 \%$ \\
\hline
\end{tabular}

Son varios los datos interesantes que conviene analizar. Por ejemplo, aparece que las actividades netamente turísticas no fueron las de mayor preponderancia en el lugar, debido a que las diversas modalidades del comercio las colocaron en segundo lugar. Sin embargo, es viable aceptar que buena parte del predominio del rubro comercial, responde justamente al turismo, por la demanda de artículos varios por parte de los visitantes que llegan a la isla por cualquier medio. Sería difícil explicar cifras tan elevadas a partir solamente de las compras de la población local. De esa forma, si se suman los totales del comercio en general y de las actividades claramente asociadas con el turismo, se acumularía 61,8 por ciento del total de ingresos generados en la isla. Si a lo anterior se agrega la tercera actividad con más presencia (transporte y comunicaciones) se completarán dos tercios del total.

El comportamiento de las subramas relacionadas con el transporte también merece comentarse. Aparte de que la actividad sustantiva de Cozumel es el movimiento de cruceros turísticos, el nivel de ingresos obtenidos de ninguna manera alcanza la 
magnitud esperada. Esta situación puede tener una explicación sencilla, puesto que tan baja captación demuestra que las compras de boletos para las travesías (incluso las aéreas) se efectúan fuera de la isla, razón por la cual los recursos económicos quedan contabilizados en otros lugares, la mayor parte de ellos en el extranjero.

Se presenta así una situación paradójica, pero esta pérdida en la captación de montos de ingresos significativos provenientes del turismo es indicativa del nivel de internacionalización y globalización alcanzado por la economía local INEGI, (s/f) Censo Económico 2009, en donde las compras se originan en diversos países. De todas formas, la otra parte del postulado teórico sobre la especialización de Cozumel en actividades turísticas se cumple, ya que su economía depende, directa o indirectamente, de este sector. En realidad, un alto porcentaje de la población local interactúa con los turistas cada día; por ejemplo, operadores locales, taxistas, meseros, guías, personal de hoteles y restaurantes, entre otros. Un grupo clave en este sector son los operadores de tours, puesto que cerca del 60 por ciento de los pasajeros de los cruceros compran visitas guiadas. Por lo tanto, son las actividades del sector terciario las que aportan más recursos económicos al municipio, especialmente las comerciales y de servicios de alojamiento temporal y de preparación de alimentos y bebidas.

Para terminar este apartado debe señalarse la importancia de la industria extractiva, la cual registró cerca del 9 por ciento de los ingresos del municipio, gracias a la extracción de roca caliza y arena. En el apartado sobre localización geográfica se hizo mención de la empresa Calizas Industriales del Carmen 2003 productora de materiales para la construcción, dirigidos a mercados de alto nivel económico en México y los Estados Unidos, de donde se generan 45 millones de dólares anuales (en promedio), parte de los cuales se queda en la isla a través de salarios, compra de servicios y bienes, etcétera.

Lo más relevante de encontrar esta actividad cerca de la isla es la demostración de que a nivel municipal Cozumel demuestra cierta diversificación en su estructura económica (con excepción del sector primario), la cual deberá revisarse con cuidado pues podría significar un argumento adicional para explicar su posición de cierto auge económico. Incluso, podría perfilar un modelo de aprovechamiento de otros recursos locales en un centro sobre-especializado en el turismo, y dimensionar su capacidad para sostener un desarrollo económico más estable y sólido a partir de su diversificación económica.

\section{Afectaciones por el turismo de cruceros en Cozumel}

La interacción sostenida entre la población local de esta Isla y los miles de visitantes que arriban a ella cada día puede reconocerse como un claro factor de crecimiento económico. Pero a la vez también repercute en otras esferas de la vida de los residentes. En una investigación como la presente sería una omisión significativa dejar de hacer referencia a diversos inconvenientes de trascendencia. Es un hecho que cuando se evalúa el éxito de la actividad turística en este destino, más allá de la valoración económica, es obligado involucrar aspectos socioculturales y otros de índole ambiental con perspectivas poco alentadoras. Algo similar ocurre en los demás destinos del Caribe mexicano, tal como lo afirma Chan Cob (2003) al referir una serie de afectaciones que se resumen en el Cuadro 7. 
Cuadro 7. Afectaciones en los ámbitos natural, económico, urbano y sociocultural en Cozumel derivados del turismo. Fuente: Elaborado sobre la base de Chan Cob, 2003.

\begin{tabular}{|c|c|c|}
\hline En el contexto natural & En el contexto económico & En los contextos urbano y sociocultural \\
\hline $\begin{array}{l}\text { - Se registra conflicto entre el proyecto } \\
\text { del Muelle Puerta Maya y los grupos } \\
\text { ambientalista que entre } 1993 \text { y } 1996 \\
\text { defendieron al Arrecife Paraíso. La } \\
\text { controversia alcanzó dimensiones } \\
\text { internacionales en 1996, al presentarse } \\
\text { una denuncia ante la Comisión de } \\
\text { Cooperación Ambiental del Tratado de } \\
\text { Libre Comercio de América del Norte } \\
\text { (Según la Comisión para la Cooperación } \\
\text { Ambiental, CCA, 1997 citada por Chan } \\
\text { Cob, 2oo3). } \\
\text { - El Programa de Manejo del Parque } \\
\text { Nacional Arrecifes de Cozumel considera } \\
\text { que los muelles provocan un impacto } \\
\text { directo que va de moderado a bajo, por } \\
\text { la destrucción de estructuras coralinas } \\
\text { y suspensión de sólidos debido a la } \\
\text { construcción y operación derivadas de las } \\
\text { maniobras de atraque. } \\
\text { Asimismo, en el Área Natural Protegida } \\
\text { se considera que el segmento de cruceros } \\
\text { provoca impacto indirecto moderado por } \\
\text { el tráfico de embarcaciones y ruido, así } \\
\text { como por descarga de desechos líquidos } \\
\text { (aguas residuales, combustibles y aceites) } \\
\text { y sólidos. } \\
\text { • Aunque no se han dado con una } \\
\text { frecuencia alarmante, en la isla se } \\
\text { recuerdan algunos accidentes de navíos, } \\
\text { que en cierto momento pudieron haber } \\
\text { afectado a los ecosistemas marinos de } \\
\text { gran fragilidad, como los arrecifes de coral. }\end{array}$ & $\begin{array}{l}\text { a actividad comercial es condición } \\
\text { oligopolio, las plazas comerciales } \\
\text { las terminales marítimas tienen } \\
\text { esos directos desde los muelles y } \\
\text { es promociona desde el interior de } \\
\text { cruceros. Los comerciantes locales } \\
\text { man que hay una competencia desleal } \\
\text { an manifestado su temor de ser } \\
\text { plazados ya que los establecimientos } \\
\text { centro de la isla se ven afectados. } \\
\text { ay excesivo crecimiento de cadenas } \\
\text { ernacionales de joyerías que han } \\
\text { plazado a otros sectores comerciales } \\
\text { la principal avenida turística. } \\
\text { a vecindad de la dársena de los } \\
\text { nsbordadores de carga locales, en } \\
\text { ación con el muelle turístico y la } \\
\text { canía con el muelle de cruceros de } \\
\text { erta Maya, ha generado conflictos por } \\
\text { rioridad que el gobierno concede } \\
\text { ocasiones al atraque de cruceros en } \\
\text { ación con la llegada de insumos a la isla. } \\
\text { os taxistas manifiestan inconformidad } \\
\text { que sean los promotores de cruceros } \\
\text { la isla los que transporten a los turistas } \\
\text { ia los clubes de playa. Consideran } \\
\text { los promotores incurren en prácticas } \\
\text { nopólicas; se les concede la concesión } \\
\text { a prestar el servicio de transporte } \\
\text { rítimo entre Cozumel y Playa del } \\
\text { men, y ahora usan parte de estas } \\
\text { barcaciones como taxis acuáticos, en } \\
\text { juicio del sector taxista local. }\end{array}$ & $\begin{array}{l}\text { arencia de medidas regulatorias } \\
\text { to a la preferencia de taxistas } \\
\text { los turistas en detrimento de la } \\
\text { la población local. En las horas } \\
\text { ayor movimiento de cruceros } \\
\text { prefieren circular en las zonas } \\
\text { ercanas a los muelles y no } \\
\text { a demanda de la población local. } \\
\text { con mayor presencia de } \\
\text { avenida principal se vuelve casi } \\
\text { le para los peatones, resulta } \\
\text { ara los 1o mil turistas que en } \\
\text { descienden al arribar varios } \\
\text { multáneamente. } \\
\text { ución ha aumentado en forma } \\
\text { al a la llegada de cruceros. } \\
\text { de la tripulación, así como } \\
\text { nforman la principal demanda de } \\
\text { exuales. } \\
\text { cación del turismo de cruceros } \\
\text { te las localidades de destino } \\
\text { te adopten una actitud } \\
\text { ta en relación con los recursos } \\
\text { naturales. Esto en ocasiones } \\
\text { nodificación de las tradiciones de } \\
\text { l que afectan su cultura, ambiente } \\
\text { l. } \\
\text { de cruceros, mayormente } \\
\text { cano, demanda servicios y } \\
\text { similares a los de su país, } \\
\text { icia la llegada de cadenas } \\
\text { nales y adopción de costumbres y } \\
\text { ida ajenas a las locales. Se tiende } \\
\text { culturación, }\end{array}$ \\
\hline
\end{tabular}

De los efectos más sentidos señalados antes pueden mencionarse estudios científicos que consideran a los muelles de cruceros como provocadores de la destrucción de estructuras coralinas. Del mismo modo se califica el alto número de navíos como elementos perjudiciales del área Natural Protegida de la isla (Chan Cob, 2003). Han sido relativamente frecuentes los accidentes de navíos, mismos que en cierto momento pudieron haber afectado a los ecosistemas marinos ya de por sí frágiles (en especial los arrecifes de coral).

Puede coincidirse con este mismo autor al dar a conocer que en Cozumel existen preocupaciones en el orden económico interno, como los desplazamientos de empresarios locales por las cadenas turísticas transnacionales; concentración de los beneficios hacia el segmento de la joyería y de las macro plazas comerciales de las terminales de cruceros; fuga de divisas, pues la mayoría de la mercancía y productos turísticos no se producen en la comunidad; y el impacto del turismo en los precios locales, lo cual produce inflación y encarecimiento de la canasta básica de la localidad. El costo creciente de residir en la localidad se resiente en mayor grado por la población cuya actividad está fuera del turismo.

En el aspecto social se enfrenta otra situación contradictoria; por una parte, en apartados anteriores se hizo referencia a la herencia histórica y cultural de la que se beneficia la población local. Sin embargo, el contacto constante con visitantes de diversas partes del mundo está perfilando la transculturación como un problema cada vez más vigente, manifestado por el decreciente porcentaje de hablantes de lengua maya, lo cuales, además, cambian sus patrones de comportamiento para adaptarse al turismo extranjero. Este cambio se ve reflejado también en el aumento de delitos, por lo general 
provocados por inmigrantes no integrados a la localidad. Tampoco se pueden soslayar otras consecuencias tales como el aumento de enfermedades, así como mayor prostitución, drogadicción y alcoholismo, problemáticas siempre asociadas al turismo de playa.

Sin duda los beneficios de la internacionalización de la isla son trascendentes y llegan a impactar de manera favorable la balanza de divisas de México. Pero también van tomando forma procesos que modifican los marcos sociales, económicos y culturales; al transformarse lo que es local, estatal, regional y nacional en global. De la misma forma, se modifican las estructuras de poder económico, político y cultural, enfocándose en primer lugar a la expansión del capital a través del fomento al consumo, lo que ha generado la creación de un mayor número de productos y empresas, con el desafortunado desenlace del incremento de los índices de pobreza y desempleo (Palafox, 2003).

En ese entorno adverso siempre será recomendable instrumentar acciones para revertir los posibles daños. Por ejemplo, está en marcha un Plan de Acción para el Manejo Compartido de un Destino de Cruceros, dirigido a procurar un manejo sostenible de Cozumel al nivel que demanda un destino de cruceros de clase mundial. A fin de cuentas, el éxito de Cozumel está relacionado con sus recursos naturales, realidad que obligará a encontrar el debido equilibrio entre el medio físico, las actividades económicas y cultura locales.

\section{Conclusiones y consideraciones a futuro}

En este trabajo se revisó la favorable vocación de Cozumel hacia el turismo de cruceros. Ubicada a una distancia moderada (en términos náuticos) tanto de las costas de los Estados Unidos (y en parte también de Canadá) como del canal de Panamá, le dan franca accesibilidad al mayor mercado de "cruceristas" del planeta. Esta cercanía permite aplicar el principio de Hirschman al respecto de que entre regiones complementarias se facilita el flujo de recursos entre la región rica (en este caso los países de América del Norte) y la región menos desarrollada (costas mexicanas en general y Cozumel en particular). Desde el enfoque teórico mencionado y de acuerdo con los resultados de la presente investigación hay elementos suficientes para justificar, en parte, el éxito de la isla como centro turístico y crucerista de calidad mundial.

El análisis de la disponibilidad de infraestructura como segundo elemento favorable refleja una planeación de primer nivel, al disponer de instalaciones especializadas en la recepción de grandes cruceros, pero situadas a distancia de las otras destinadas para transbordadores locales, evitando cualquier interacción entre ambas infraestructuras. De igual manera se asentó la terminal de ferrys, también a buena distancia de las otras dos. En consecuencia, se reciben todo tipo de navíos de pasajeros, sin que alguna obstaculice la operación de las demás, contando también con equipamiento moderno y administración eficiente a cargo de la Administración Portuaria Integral respectiva. A lo anterior se suma la presencia de numerosos hoteles de todo tipo de tarifas, restaurantes y bares, igualmente accesibles a varios tipos de visitantes, si bien predominan los de alta capacidad económica.

El tercer parámetro analizado se refirió a las condiciones socioeconómicas de los residentes locales. Se postuló de inicio que tanto la población como la estructura económica de este municipio deberían estar centradas en los servicios relativos al turismo, según los señalamientos de algunos autores citados.

Empezando por las características de la población, se encontró un nivel educativo de los residentes de la isla superior al promedio nacional. Más aún, la gente del lugar cuenta con cierto grado cultural, debido a su contacto constante con diversos ejemplos de riquezas culturales. Es poco común en el ámbito turístico de México (y, tal vez, de 
toda el área caribeña) encontrar niveles tan favorables. Estas actividades suelen estar atendidas por personal de baja condición educativa, ingresos mínimos, generalmente inmigrante y, por ende, con poco apego a los valores locales.

En términos económicos, también se confirmó una concentración notable de la población ocupada empleada en comercio y servicios (el 83 por ciento del total), actividades estrechamente asociadas con el turismo. Pero fue relevante determinar que esa especialización significativa se repitió a escala sectorial, ya que las actividades comerciales y de servicios aportaron el 78 por ciento de los ingresos totales del municipio.

En contraste fue inesperado identificar una presencia importante de la industria extractiva (9 por ciento de los ingresos registrados), confirmada a nivel de las principales subramas donde la minería de calizas aporta, por sí sola, cerca del 7 por ciento de las ventas reportadas de todo el municipio de Cozumel. Este resultado da pauta para plantear la posibilidad de diversificar la actividad económica de otros centros turísticos mexicanos, ya que si es posible alcanzar cierta diversificación en un municipio de tamaño reducido y en un entorno poco favorable (en apariencia) para desarrollar otros sectores, seguramente los lugares situados sobre el continente podrían tener mayores perspectivas.

Con estos resultados puede aceptarse que Cozumel cumple los conceptos citados al inicio de este escrito, respecto al peso protagónico que presentaron rubros relativos al turismo (como el transporte, comercio y servicios de hospedaje, etcétera). Y también resalta la relativamente baja captación de ingresos por transporte, de donde se concluye que las compras de pasajes y servicios de transportación (y seguramente reservaciones hoteleras) se efectúan en lugares ajenos a la economía local, con menores beneficios de los esperados para los residentes. Esta última circunstancia permite inferir el grado de internacionalización y globalización alcanzada por la economía local, en el ámbito de la dependencia que guarda respecto a la venta de servicios que ocurren fuera de su territorio.

Para terminar, conviene reiterar que los principales resultados de la presente investigación confirman a Cozumel como un puerto destacado dentro de los cruceros turísticos del Caribe, gracias a combinar diversidad de atractivos naturales y antrópicos; una ubicación geográfica cercana al mayor mercado de cruceristas del mundo; equipamiento multimodal y especializado con el que cuenta y a la disponibilidad de personal dedicado preferentemente al comercio y los servicios turísticos. Pero también su desempeño exitoso debe asumirse, en parte, a cierta diversificación de sus actividades económicas que favorecen más empleo y demanda de servicios locales.

Debe reiterarse que el presente trabajo se enfocó a la búsqueda y explicación de factores (más allá de lo local) que justificaran la ventajosa posición alcanzada por Isla de Cozumel dentro del turismo mundial de cruceros. Por lo anterior, se dejó de lado ahondar en los ángulos negativos que enfrenta, provocadas por las actividades que le han dado ese protagonismo a nivel mundial. Para establecer una visión más completa y objetiva se hace deseable otro trabajo similar, ahora orientado a identificar las principales problemáticas relacionadas con la economía lugareña y que posibilite dimensionar con precisión los beneficios que ha obtenido Cozumel de su cercanía al Canal de Panamá. La accesibilidad a ese paso interoceánico seguramente representa un potencial significativo de desarrollo para éste y otros puertos mexicanos de todo tipo; opción que sigue pendiente de estudiarse con el cuidado que amerita.

Agradecimiento. La presente investigación forma parte de un proyecto desarrollado en el Instituto de Geografía de la Universidad Nacional Autónoma de México (UNAM), financiado por el Programa de Apoyo a Proyectos de Investigación e Innovación Tecnológica (PAPIIT) Clave IN300512 de la misma institución, denominado "Carácter Geoestratégico de tres islas de México, Cedros, Carmen y Cozumel: desde la perspectiva de su territorio, población y economía”. 


\section{Q Bibliografía}

》Administración Portuaria Integral de Quintana Roo (API QROO) (2013). Recuperado de http://www.apiqroo.com.mx/v2013/estadistica (15/04/2014)

»Aguilar, J., Chapapría, V., Yepes, V. (200o) El Turismo de cruceros como modalidad del transporte de pasaje. En Transporte Marítimo. José V. Colomer, Alfredo García (Eds.). CIT200o. España. Recuperado de http://personales.upv. es/vyepesp/AguilarEstebanYepes.pdf (30/01/2014).

"Asuad, N. (2001) Economía regional y urbana. Puebla: Benemérita Universidad Autónoma de Puebla.

"Ayuntamiento de Cozumel (2005-2008). Protegiendo la herencia natural de Cozumel: Plan de Acción para el manejo compartido de un destino de cruceros. Recuperado de http://www.eco-index.org/search/pdfs/1201report_1.pdf. (18/03/2014).

»Barragán, J. (1987) Las Áreas de Influencia Portuaria (A.I.P) análisis Geográfico Regional: Aspectos Metodológicos y Conceptuales. Revista Estudios Regionales, (17) 17-39. Recuperado de http://www.revistaestudiosregionales.com/pdfs/ pdf214.pdf (10/12/2016).

" Cañada, E.; Gascón, J. (2007) Turismo y desarrollo: herramientas para una mirada crítica. Managua: Fundación Luciérnaga- Acción por un Turismo Responsable. Enlace.

»Caravaca, I. (1998) Los nuevos espacios ganadores y emergentes. Eure. XXIV (73).

"Castells, Manuel (1996). The information Age. The Rise of the Network Society. Vol.1. Massachusetts: Blackwell Publishing.

"Castells, M. (1999). La era de la información económica: economía, sociedad y cultura. Madrid: Ed. Alianza.

" Centro de Estudios Superiores en Turismo (CESTUR). (s/f). Estudio sobre productos y servicios diferenciados en los principales destinos de cruceros. Reporte Ejecutivo. Recuperado de http://cedocvirtual.sectur.gob.mx/janium/ Documentos/cruceros_resumen_ejecutivo.pdf (11/01/2014).

"Chan Cob, J. (2003) Turismo y financiamiento para la conservación y el desarrollo sustentable del Caribe mexicano: El caso de la isla de Cozumel y los cruceros. Desarrollo sustentable del turismo. Contribuciones académicas del 1er Congreso Internacional del 21 al 23 de mayo de 2003, 31-52. Cancún: Universidad de Quintana Roo Alejandro Palafox Muñoz Coord.

" Glade, W., Anderson, C. (1963) The political economy of Mexico. Two studies. Wisconsin: University of Wisconsin.

" Gobierno de Quintana Roo (s/f). Programa de Diversificación del Turismo. Recuperado de http://www.qroo.gob.mx/plan-de-accion/programa-4diversificacion-y-desarrollo-del-turismo (24/07/2018).

» Hirschman, A. (1958) The strategy of economic development. New Haven: Yale University.

» Instituto Nacional de Ecología (INE) (1998) Instituto Municipal de Investigación y Planificación. Programa de Manejo Parque Marino Nacional Arrecifes de Cozumel, México. Recuperado de http://www.inecc.gob.mx/descargas/publicaciones/174. $\operatorname{pdf}(15 / 01 / 2014)$. 
" Instituto Nacional de Estadística y Geografía (INEGI) (s/f). Censo Económico 2009. Recuperado de: http://www.inegi.org.mx/est/contenidos/espanol/ proyectos/censos/ce2009/. 27/03/2014.

"Instituto Nacional de Estadística y Geografía (INEGI) (s/f) Censos de Población y Vivienda 1990, 2000 y 2010. México. Recuperado de http: www.censo 2010.org. $m \times(15 / 04 / 2014)$.

" Instituto Nacional de Estadística y Geografía (INEGI) (s/f) Marco Geoestadístico Nacional 2010. Recuperado de http://www.inegi.org.mx/geo/contenidos/ geoestadistica/m_geoestadistico.aspx.15/04/2017.

»Navarro, J. (1994) Aproximación Analítica a los Sistemas Portuarios y su Aplicación a los Puertos Valencianos. Investigaciones Geográficas, 12, 147-161, Recuperado de http://rua.ua.es/dspace/bitstream/10045/501/1/Navarro\%20 Vera-Aproximacion\%20analitica.pdf (18/03/2014).

» Myrdall, G. (1979 [1959]) Teoría económica y regiones subdesarrolladas. México: Fondo de Cultura Económica.

» Padilla, L. y Molina, I. (2013) La isla de Cozumel: espacio preferencial del turismo de cruceros en el Caribe. En Espacios insulares y de frontera, una visión geográfica, Coordinador: Grimaltgelabertu, Miquel. Palma de Mallorca: Universidad de las Islas Baleares.

"Palafox, A. (2003) La modernidad: utopía del turismo sustentable. En: Desarrollo sustentable del turismo. Contribuciones académicas del 1er Congreso Internacional del 21 al 23 de mayo de 2003, pp 103-112. Cancún: Universidad de Quintana Roo Alejandro Palafox Muñoz Coord.

» Pozo, C., Armijo, N., Calmé, S. (Editoras) (2011) Riqueza Biológica de Cozumel. Un análisis para su conservación. México: Comisión Nacional para el Conocimiento y Uso de la Biodiversidad (CONABIO), Colegio de la Frontera Sur (ECOSUR), Gobierno del Estado de Quintana Roo y Programa de Pequeñas DonacionesMéxico.

"República de Panamá. Autoridad de Turismo de Panamá. Boletín Estadístico (2013) Recuperado de http://www.atp.gob.pa/sites/default/files/documentos/ resumen_ejecutivo_2013.pdf(22/03/2014).

"Secretaria de Comunicaciones y Transportes (SCT) (2002 a 2013) Anuarios estadisticos de puertos de México. 2002 a 2013. Cancún: Estado de Quintana Roo.

" Secretaria de Turismo (SECTUR) (2013) Estudio de competitividad turística del destino Cozumel, Agendas de Competitividad de los Destinos Turísticos de México. Cancún: Universidad de Quintana Roo. Recuperado de: http://www.cmic.org. $\mathrm{mx} /$ comisiones/sectoriales/turismo/2015/DOC_VIG_2015/PDF-Cozumel.pdf (8/08/2018).

"Soros, G. (1999) El sistema capitalista global. En: La crisis del capitalismo global. La sociedad abierta en peligro. España: Plaza \& Janés. Recuperado de http: // www.economia.unam.mx/profesores/eliezer/soros.pdf (30/03/2014).

»Valadez, R. (2017) Cozumel el mejor destino de cruceros. Negocios. Milenio.com. Recuperado de: http://www.milenio.com/negocios/cozumel-turismo-crucerossectur-amepact_o_994100598.html (25/03/2014). 


\section{Lilia Susana Padilla y Sotelo / padilla@igg.unam.mx}

Doctora en Geografía por la UNAM. Académica en el Instituto de Geografía y Profesora del Posgrado de Geografía en la misma institución. Pertenece al Sistema Nacional de Investigadores del CONACyT, Miembro de la Academia Mexicana de Ciencias, de la Academia de Geografía de la Sociedad Mexicana de Geografía y Estadística y de la. Asociación Mexicana de Ciencias para el Desarrollo Regional. Desarrolla investigación en el campo de población y ambiente, así como en la línea de sustentabilidad social.

\section{Armando García de León Loza / armandox@igg.unam.mx}

Ingeniero Químico Metalúrgico y Maestro en Geografía por la UNAM. Académico del Instituto de Geografía, UNAM, entidad en la cual ocupó la Secretaria Técnica de Vinculación, hoy día adscrito al Departamento de Geografía Económica. Es Profesor de Asignatura en el Colegio de Geografía-UNAM. Se especializa en estudios regionales. Tiene diversos trabajos científicos basados en métodos estadísticos para la clasificación multivariada de unidades territoriales mediante Sistemas de Información Geográfica. 